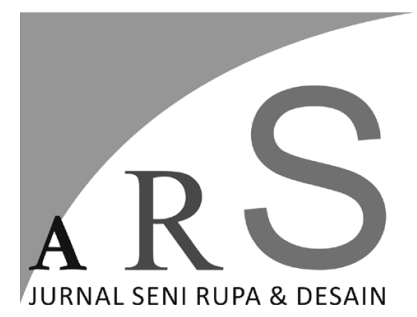

Volume 21 Nomor 2 - Agustus 2018

\section{TRANSFORMASI KRIYA DALAM BERBAGAI KONTEKS BUDAYA PADA ERA INDUSTRI KREATIF}

\author{
Alvi Lufiani \\ Program Studi Kriya Seni, Jurusan Kriya, \\ Fakultas Seni Rupa, Institut Seni Indonesia \\ Yogyakarta
}

\begin{abstract}
ABSTRAK
Transformasi yang ada dan terjadi pada ranah kriya saat ini merupakan sebuah konsekuensi dari pengaruh informasi dan teknologi global yang berdampak di berbagai bidang. Aplikasi teknologi tinggi pada proses perwujudan bidang kriya menjadikan produk kriya bertransformasi menjadi karya yang kaya karena memadukan unsur seni, teknologi, ekonomi, budaya, personal dan tangan. Pada era industri kreatif dimana kriya menjadi salah satu sub sektornya, transformasi yang ada adalah keniscayaan karena secara tidak langsung merefleksikan bagaimana kondisi sosio cultural masyarakat yang ada. Selain tentu saja sebagai upaya meningkatkan pendapatan karena produk yang dihasilkan bersifat inovatif dan distingtif. Topik tulisan ini menarik untuk dikaji karena melihat sisi lain dari transformasi yang ada di seni kriya.Transformasi tersebut tentu dilihat positif dan memberikan keuntungan bagi masyarakat dan kriyawan Indonesia.Temuan dari tulisan ini adalah bagaimana sinergi yang kuat antara berbagai pihak seperti pengrajin, kriyawan, akademisi, praktisi dan pemerintah akan menghasilkan karya kriya berkualitas, sustain, dan mampu bersaing di pasar global tanpa meninggalkan akar kultur yag dimiliki bangsa Indonesia.
\end{abstract}

Kata kunci: transformasi, kriya, teknologi

\section{ABSTRACT}

The global information and technology has brought about transformation in all domains, including craft. The application of high technology in craft creation process results in 'rich' products for those items are reflections of art, culture, economy, technology, personal desire, and skill combined together. In the creative industry, where craft is one of the sub sectors, transformation is unavoidable since it mirrors the socio-cultural condition of the society in which it is created. This paper studied craft transformation in relation to the craftmen, academics, practitioners, and goverment. The result of this research showed that the transformation happened in craft brought advantage to those stake holders.

Keywords: transformation, craft, technology 


\section{Pendahuluan}

Craft, atau seni kriya saat ini semakin dikenal masyarakat luas sebagai salah satu cabang seni yang bertransformasi. Tranformasi yang terjadi pada dunia kriya merupakan suatu realita menarik untuk diperbincangkan. Alasannya karena perubahannya ada baik pada sisi intra maupun ekstra estetik kriya. Dari segi intra banyak perubahan fisik yang cukup fenomenal pada kriya. Sedangkan dari segi ekstra, salah satunya adalah pada segi perannya. Seperti yang ditegaskan oleh Bruce Metcalf, kurator dan kriyawan kontemporer bahwa kriya itu berubah, seperti halnya masyarakat juga berubah. Manusia dapat saja merancang apa dan bagaimana kriya itu didefinisikan sesuai dengan keinginan dan hasrat spesifik mereka. Terkait dengan era industri kreatif, apa yang terjadi pada kriya sekarang amat mempengaruhi dan dipengaruhi oleh para pelaku industri kreatif sektor kriya itu sendiri.

Kriya merupakan suatu hasil atau konstruksi budaya yang tidak terpisahkan dari kehidupan manusiadi banyak tempat khususnya Indonesia. Kerapkali dikoneksikan dengan suatu yang tradisional, perubahan yang terjadi pada kriya dewasa ini dapat dikatakan kompleks. Hal ini karena status kriya sudah merambah pada segi estetika dan konseptualnya. Estetika yang ditampilkan oleh produk kriya dulunya merupakan sebuah representasi budaya dari masyarakat yang ada. Semakin tinggi budaya suatu masyarakat, akan semakin tinggi juga karya kriya yang tercipta. Salah satunya adalah keris, batik, wayang dan karya kriya lain yang tidak hanya indah dilihat namun juga elok nilai filosofinya. Di sisi lain, kriya juga merupakan representasi karya budaya masyarakat luas yang erat dengan kehidupan sehari hari. Contohnya adalah elemen interior rumah, alat dapur, furnitur atau benda-benda yang ada dan dekat dengan aktivitas manusia juga merupakan sebuah karya kriya.

Transformasi dan ekspansi yang terjadi di dunia kriya tidak lepas dari apa yang terjadi di berbagai negara. Baik negara maju maupun berkembang. Seiring dengan perkembangan teknologi yang semakin tak terbendung, segala informasi terkait perubahan itu pada akhirnya saling mempengaruhi. Saat ini, seniman kontemporer berpaling pada kriya dalam menciptakan karya-karyanya. Mereka mengklaim tentang nilai tinggi yang ada pada estetika handmade kriya dan acapkali menolak nilai efisiensi pada produksi estetika mereka. Efisiensi, sebuah nilai yang selama ini terlihat begitu diagungkan oleh kaum seniman kontemporer. (Poser, 2008:80) Estetika handmade atau buatan tangan yang lekat dengan kriya bahkan menggantikan nilai efisiensi tersebut. Estetika handmade diasosiasikan dengan sense of authentic dalam dunia yang serba inauthentic. Di sisi lain walaupun otentik, keberadaan alat atau teknologi dalam proses berkarya mereka juga tidak dapat dihindari. Fenomena ini menarik sekaligus kontradiktif, karena para seniman kontemporer itu berusaha menunjukan secara nyata nilai autentik karya pada aspek konstruksi dan waktu yang dicurahkan pada proses pembuatan karya. Alasannya karena selama ini, nilai-nilai itulah yang lekat dengan produk atau karya kriya.

Seperti yang dikatakan oleh Fang Wu Tang bahwa kriya itu sejatinya tidaklah statis, melainkan memiliki kemampuan untuk senantiasa berevolusi, bertransformasi dan beradaptasi pada kehidupan modern. (Tung, 2012:2) Nilai yang terakhir, yaitu adaptasi nyatanya yang memiliki kaitan langsung dengan masyarakat. Di tengah arus globalisasi dan kemajuan teknologi yang tak terbendung, adaptasi fleksibel yang terjadi pada seni kriya nyatanya sebuah keniscayaan. Ditambah dengan era industri kreatif yang terjadi di belahan dunia manapun, maka amat menarik untuk mengkaji kelenturan kriya dalam menyelaraskan diri pada masyarakat dalam konteks yang beragam. Baik dari konteks budaya, sosial dan ekonomi. Pembahasan tentang hal ini juga kritikal karena adanya paradoks yang terjadi di dunia kriya. Di satu sisi semakin banyak kriyawan yang kembali pada penekanan keterlibatan tangan. Di sisi lainnya, keterlibatan teknologi pada aktivitas kriya merupakan sebuah kenyataan.

Ada beberapa kasus yang akan dibicarakan pada tulisan ini terkait dengan transformasi kriya yang terjadi sekarang. Pertanyaannya adalah bagaimana transformasi itu terjadi dan berpengaruh pada kehidupan kultural masyarakat dan keuntungan apa yang secara 
langsung maupun tidak langsung dapat diperoleh oleh masyarakat dengan ekspansi yang terjadi utamanya pada era industri kreatif.

\section{Dinamika Kriya Di Era Kontemporer}

Menarik untuk mencermati dinamika kriya yang berkembang sedemikian rupa, baik di Indonesia maupun manca negara. Adanya kenyataan bahwa karya kriya dapat dibuat dalam jumlah banyak dengan peralatan modern nyatanya seperti menunjukkan adanya sinergi yang kuat antara kekriyaan (craftsmanship), sentuhan tangan manusia dan kehadiran teknologi. (Tung, 2012:3) Teknologi modern tersebut memberikan kesempatan pada bidang kriya untuk tetap menciptakan karya yang yang unik sekalligus distingtif. Dewasa ini para praktisi kriya melihat adanya kaitan erat yang positif dan saling menguntungkan antara kriya dan teknologi. Adanya teknologi laser cutting, rapid prototyping, CAD, CAM dan lainnya nyatanya tidak hanya terlihat di sebuah kawasan industri, melainkan juga di studio seorang kriyawan. Teknologi tersebut telah beradaptasi dengan proses pembuatan karya kriya untuk mengembangkan dan menghasilkan sebuah karya.
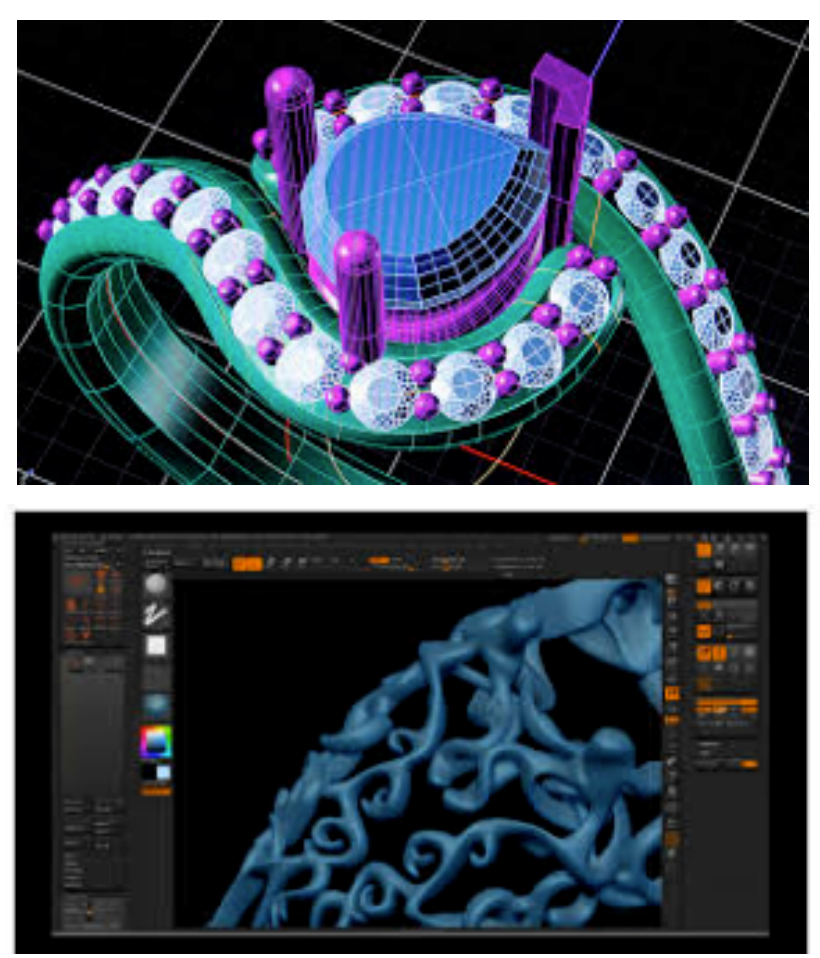

Gambar 1 dan 2. Detil desain perhiasan dengan CAD
Salah satunya seperti yang dilakukan oleh seorang jeweler, pembuat dan desainer perhiasan di Philadelphia, US, Rona Fisher. Ia yang tadinya terbiasa dengan segala peralatan tradisional dalam menghasilkan karya perhiasan akhirnya bergeser dengan menggunakan teknologi modern seperti CAD dalam proses berkaryanya. Hasil dari pengaplikasian peralatan canggih itu sejauh yang dirasakan Rona cukup memuaskan. Paling tidak dari segi waktu ia tidak perlu menyisihkan banyak waktu untuk dapat menghasilkan sebuah desain perhiasan. Konsumenpun senang karena dapat melihat seperti apa kira-kira hasil akhir perhiasan yang dipesan dengan teknologi 3 D. Memang Rona mengakui ada bagian yang hilang yaitu saat ia merasa tidak memegang alat yg biasa ia pegang dalam waktu lama. Namun melihat hasil dan keuntungan yang dirasakan, hal itu bukan merupakan masalah besar. Seperti yang dikatakan oleh Fang Wu bahwa fleksibilitas dan ketersediaan teknologi yang sejalan dengan sensibilitas kriya membuat para kriyawan mendapatkan cara yang tepat dan efektif dari segi biaya untuk menghasilkan sebuah produk, Cara seperti itu juga mempermudah prdouksi karya secara berkala namun tetap mempertahankan kualitasnya baik dari segi estetik maupun fungsinya. Dikatakan juga bahwa para kriyawan telah menemukan cara baru untuk dapat mengembangkan karya atau produk mereka untuk dapat bertahan dalam bidang tersebut. Selain itu juga untuk berkompetisi dan sekaligus menarik manfaat dari perkembangan teknologi serta menerapkannya pada produksi masal dari sebuah produk. (Niedderer, 2009)

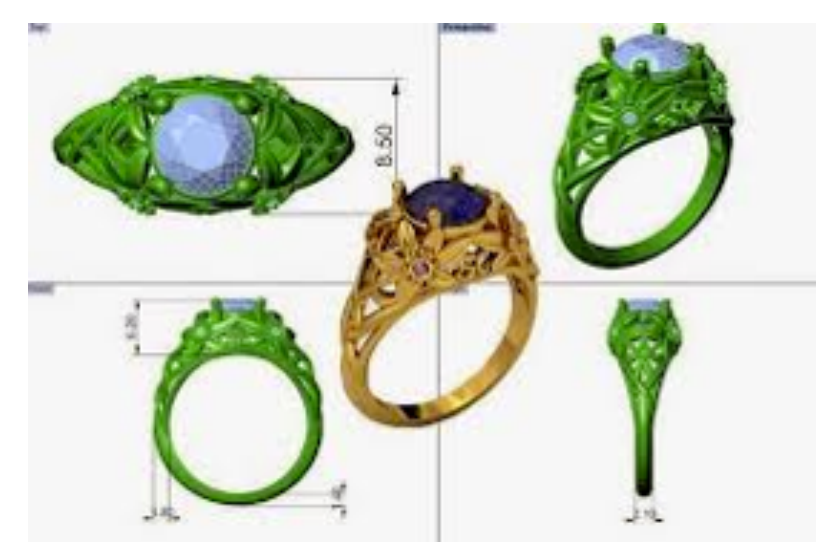

Gambar 3. Desain perhiasan tampak atas, samping dan perspektif dengan CAD. Sumber : http:// jewelrydesignsketchesideas2014.blogspot.co.id/2014 
Contoh lain diperlihatkan oleh kriyawan dengan fokus perhiasan kontemporer, Kirsten Hassenfeid, yang berdomisili di New York, Amerika. Pada sebagian besar karyanya, Kirsten menggunkn material yang jauh dari kesan mewah seperti kertas. Perhiasan tersebut dipamerkan dalam bentuk instalasi dengan mempertontonkan keindahan sebuah perhiasan yang terbuat dari kertas. Perhiasan kertas itu benar-benar sanggup menyedot perhatian khalayak dengan kemampuannya menampilkan sisi detil dan rumit sebuah perhiasan. Pengerjaan perhiasan kertas Kirsten mengguatkan teknologi laser cutting untuk menghasilkan potongan sesuai desain yang rumit. Laser cutting amat berperan pada proses ini karena pemotongan manual menggunakan gunting tangan mustahil dapat menghasilkan kualitas sejenis. Tentu saja fenomena ini tidak terbayangkan sebelumya. Bagaimana sebuah karya perhiasan yang terbuat dari kertas mendapat panggungnya dan mendapat aplaus dari audiens seperti halnya perhiasan mewah lainnya. Hal ini menunjukkan sebuah dinamika dan perubahan cara pandang serta penilaian masyarakat terhadap karya kriya kontemporer. Apapun bahan atau material bukan menjadi satu- satunya faktor penentu sukses tidaknya karya tersebut di mata penikmat. Satu lagi aspek lain yang sangat penting adalah keintiman yang terjadi antara aplikasi teknologi tinggi pada karya dan keterlibatan tangan sang kriyawan yang akhirnya menghasilkan karya yang one-of-a kind.

Hal ini tentu berbeda dengan yang terjadi pada masa lampau. Kriya, yang senantiasa dilekatkan dengan imej tentang tradisonal, lokal dan sederhana, nyatanya memang mengalami trasnformasi. Di masa lalu, penggunaan alat-alat dalam tiap pekerjaan kirya identik dengan segala sesuatu yang serba tradisional dan peninggalan turun temurun. Tidak jarang para kriyawan membuat sendiri alat yang dipakai untuk menghasilkan suatu karya. Saat ini dengan segala terpaan arus globalisasi yang mempengaruhi tiap lini seni tidak terkecuali kriya, perlahan terjadi perubahan. Memang, masih banyak kriyawan atau pengrajin yang mempertahankan penggunaan alat-alat tradisional dalam aktivitas bekerjanya, namun banyak juga yang beradaptasi dengan penggunaan teknologi modern seperti yang disebutkan di atas.

Pada era industri kreatif dimana kriya merupakan sub sektornya, penggunaan teknologi yang bersentuhan erat dengan sentuhan tangan manusia tentunya bisa menjadi sebuah keunggulan tersendiri. Ditambah lagi dengan keunikan budaya yang beragam dan masingmasing keragaman itu memiliki keunikan yang distingtif, sehingga menjadi produk yang inovatif. Pada bidang kriya, seperti yang dikatakan oleh Nithikul Nimkulrat bahwa craft (kriya) dipahami tidak hanya sebagai suatu cara untuk menghasilkan sesuatu dengan tangan, namun yang lebih penting adalah sebagai cara
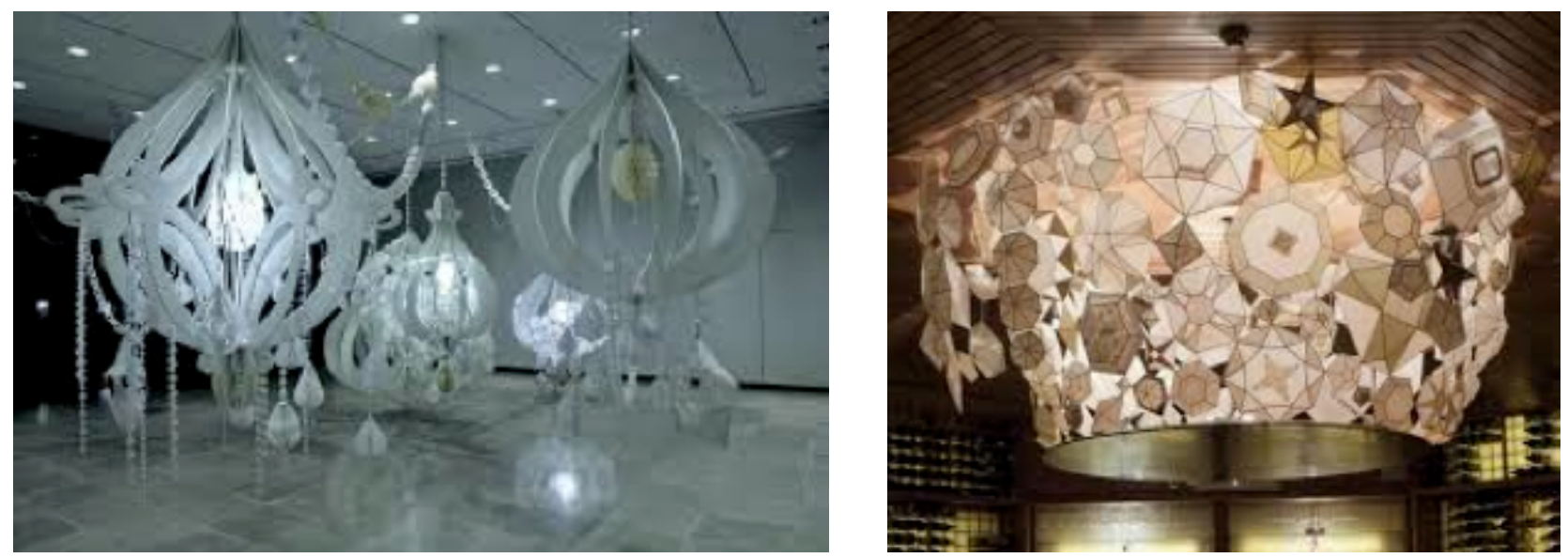

Gambar 4 dan 5. Karya perhiasan kertas Kirsten Hassenfeid dengan laser cutting. Sumber. Kirsten Hassenfeld: http://www.bellwethergallery. com/artistsindex_01 

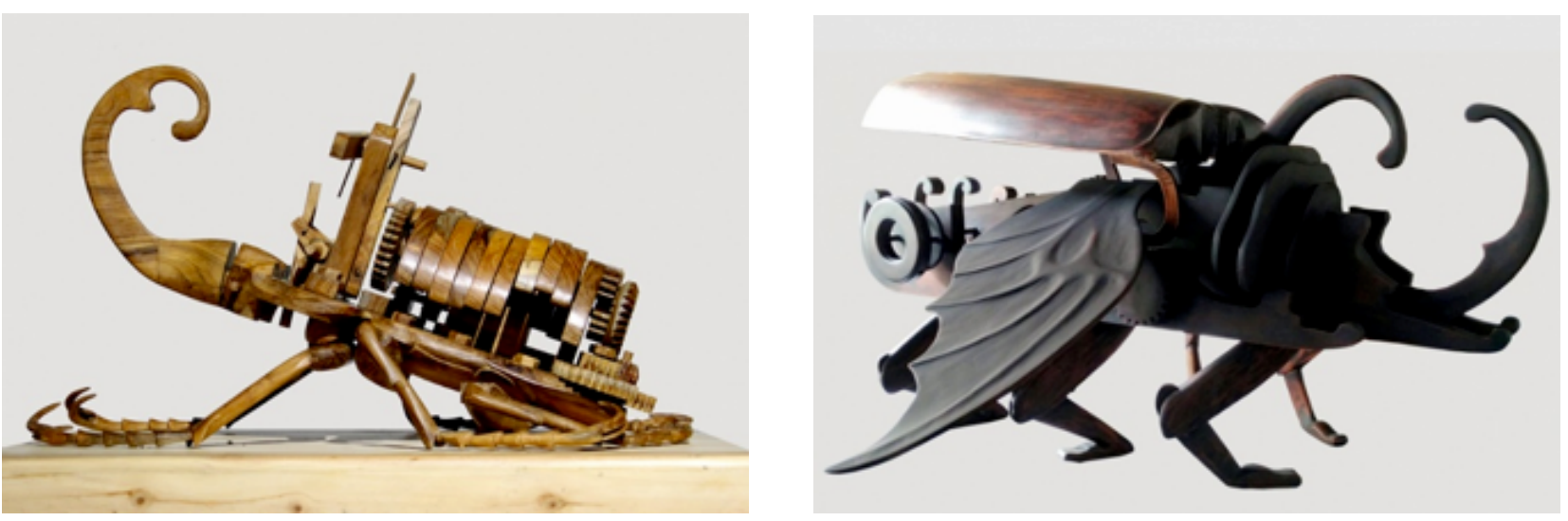

Gambar 6 dan 7. Kumbang Kinetik karya Dedy Shofianto. Terbuat dari kayu jati, finishing Sumber : Sangkling (2015)

berpikir melalui tangan dengan memanipulasi material dan alat. (Nimkulrat, 2012:7) Penggunaan diksi manipulasi di sini memang dapat dipahami beragam, tergantung konteks. Pada kali ini penulis melihat kata manipulasi lebih ke arah positif, yaitu bagaimana seorang kriyawan dapat bermain-main dengan material dan menjadikannya sebagai unsur penting dalam berkarya kriya. Lebih lanjut ditegaskan oleh Gray dan Burnett bahwa kriya merupakan sebuah proses dinamis tentang mempelajari dan memahami melalui pengalaman mengolah beragam material. (Gray, C., \& Burnett, 2009:51) Glen Adamson, seorang kritikus kriya berpengaruh bahkan menegaskan bahwa kriya adalah cara berpikir melalui beragam kegiatan. Jadi tidak hanya berkutat dengan material, alat atau proses melainkan segala sesuatu termasuk konsep dan symbol. Masalah intra dan ekstra estetik tentu termasuk di dalamnya.

Beragam pemikiran di atas nyatanya menjadi keunggulan tersendiri bagi sektor kriya, yang tidak dimiliki oleh sektor lainnya. Adanya identitas atau genius local kuat yang dimiliki oleh suatu daerah semakin mengukuhkan produk kriya sebagai objek yang mempunyai format identitas lokal khas yang terbentuk dari material, alat, skill, dan konsep yang digunakan.

Indonesia, khususnya Yogyakarta sebagai gudang kriyawan bertalenta, terdapat seorang kriyawan muda yang konsisten untuk memadukan unsur teknologi dan sains pada karyanya. Dedy Shofianto, kriyawan lulusan ISI Yogyakarta jurusan kriya saat ini tekun menciptakan karya kriya yang terbuat dari kayu.
Karya Dedy ini termasuk dalam karya kinetik. Seni kinetik seperti yang dikutip dari kuratorial Agung Hujatnikajennong digunakan untuk menjelaskan karya-karya yang berhubungan dengan 'gerak' (movement, motion) dalam berbagai bentuknya. Dalam perbendaharaan istilah dan konsep seni rupa, istilah 'seni kinetik' (kinetic art, dari bahasa Yunani 'kinesis' atau 'kinetikos', yang berarti 'gerak'). Masih menurut Agung, di Indonesia seni kinetik belum terlalu jamak dilakukan, meskipun sudah banyak seniman muda Indonesia yang melibatkan aspek "gerak" pada karya-karyanya. Menariknya, sebagai suatu kecenderungan, atau bahkan 'isme', seni kinetik menawarkan potensi eksplorasi artistik dan filosofis yang luas, dan boleh jadi merepresentasikan situasi budaya tertentu di Indonesia. ("https://www.edwinsgallery.com/ kinetik_perkembangan)," n.d.)

Dedy Shofianto yang lahir dan besar di Jambi serta menempuh pendidikan tinggi di Yogyakarta cukup jeli dan cerdas dalam memadukan dimensi budaya, teknologi dan seni dalam karyanya. Saat ini Dedy kerap mengeksplorasi kumbang tanduk (oryctes rhinoceros) sebagai obyek karyanya. Alasannya karena selain dari segi estetika dari kumbang tersebut, juga fakta menarik bahwa di Indonesia kumbang dianggap hama dan mengganggu, sedangkan di Jepang malah dibutuhkan karena dijadikan hewan peliharaan eksklusif. Ditambah dengan kenangan masa kecil Dody di Jambi yang kerap bermain adu kumbang bersama teman-temannya. Kenyataannya karya kumbang kinetik Dedy mendapat respons positif, baik dari audiens lokal maupun manca negara. 
Selaju dengan pendapat dari Fang Wu Tung bahwa menambahkan karakter otentik pada sebuah karya dengan mengadaptasi feature lokal dapat menjadi strategi untuk mengembangkan sebuah produk. Produk yang merefleksikan perbedaan yang distingtif dan ekspresi pribadi. Karya atau produk semacam itulah yang mampu masuk ke ceruk pasar khusus sekaligus membangun identitas budaya pada pasar global. (Tung, 2012:11) Dedy dengan karya kumbang kinetiknya membuktikan hal tersebut. Kumbang kinetik juga merupakan salah bentuk transformasi karya kriya yang ada dan semakin berkembang. Karya Dedy tercipta dari aspek kekriyaan tinggi karena perlu waktu dan keuletan dalam merakit potongan-potongan kayu hingga menjadi bentuk serangga (kumbang). Tanpa skill dan kekriyaan tinggi hasilnya dipastikan tidak akan secanggih karya tersebut. Di satu sisi untuk menghasilkan karya kinetik, peran teknologi adalah sebuah keniscyaan. Di bawah ini adalah beberapa imej karya kumbang kinetik ciptaan Dedy Shofianto.

Kemampuan untuk memadukan dan menonjolkan unsur seni, teknologi, material serta kualitas taktil dari karya kriya amat diterima oleh pasar global dan modern. Selain itu juga mampu menarik perhatian di celah pasar yang lebih luas (Kalviainen dalam Tung, 2012 : 15). Hal itulah yang harus semakin diperkuat pada tiap produk kriya yang dihasilkan, baik oleh kriyawan mandiri maupun usaha kecil menengah yang kini semakin banyak hadir di Indonesia. Terkait dengan situasi terkini industri kreatif di Indonesia, Kepala Badan Ekonomi Kreatif Triawan Munaf mengatakan bahwa berdasarkan data terakhir, ekonomi kreatif memberikan kontribusi sebesar 7,38 persen terhadap total perekonomian nasional dengan total PDB sekitar 800 triliun. Dari total kontribusi tersebut, sub sektor kuliner, kriya dan fashion memberikan kontribusi sebesar 18, 15 dan kriya sebesar 15,70 persen Dari data tersebut dapat dilihat bahwa kriya memiliki potensi yang amat besar dan berkontribusi pada definisi dan pembentukan ulang model ekonomi baru (www. kominfo.go.id/content/detail).

Hal ini merupakan fakta yang menantang seluruh pelaku kriya untuk lebih giat dalam menciptakan karya-karya yang kuat, tidak sekedar menjadi pengikut trend melainkan sebagai penciptanya. Meningkatnya pendapatan pelaku usaha industri kriya serta adanya pengaruh positif dalam sosio kultur masyarakat dengan adanya transformasi karya kriya ini sejatinya dapat menjadi trigger bagi segenap pihak terkait. Selain itu seperti yang dikatakan oleh Gray and Burnett bahwa dalam kriya terdapat sebuah proses dinamis dari mempelajari dan memahami budaya melalui pengolahan aneka material dan segala atributnya (Gray and Burnett, 2009, .51). Oleh karena itu, dengan kekayaan budaya yang tak terkirakan ragamnya, Indonesia harus dapat menjadi yang terdepan dalam eksplorasi ranah inovasi kriya di era industri kreatif.

\section{Kesimpulan}

Melihat luasnya prospek dan kesempatan yang terbuka luas pagi pengembangan kriya, maka eksplorasi dari segala aspek terkait di dalamnya adalah suatu keniscayaan. Eksplorasi tersebut nantinya akan mewujud dalam bentuk transformasi maupun ekspansi kriya yang memang sudah terjadi tidak hanya di Indonesia, melainkan juga di negara lain. Transformasi yang terjadi pada ranah kriya diyakini akan memberikan dampak positif pada dinamika perkembangan kriya khususnya di Indonesia. Hal ini karena Indonesia sudah memiliki modal kekuatan dan keberagaman budaya sebagai akar kriya yang kuat.

Keunggulan budaya lokal Indonesia yang bervariasi adalah refleksi dari relasi antara manusia dan lingkungannya dalam konteks sejarah, budaya dan sosial. Oleh karena itu perlu adanya sinergi antara pelaku usaha, kriyawan, pemerintah, akademisi dan praktisi dalam memetakan pola perkembangan kriya. Hal ini bertujuan untuk menghasilkan suatu produk yang berkualitas dan distingtif, tanpa meninggalkan akar kultur yang ada. Akademisi dan praktisi yang terlibatpun tidak semata harus berlatarbelakang kriya, melainkan juga berasal dari ranah desain bahkan teknik industri atau mesin. Alasannya untuk mempermudah adanya ketersediaan peralatan modern untuk menghasilkan karya kriya kontemporer. Kesemua aspek di atas memainkan peran strategis untuk memfasilitasi pengetahuan menciptakan produk dan memperkenalkannya ke massa, yang pada akhirnya dapat menumbuh 
suburkan industri kriya. Tujuan lainnya adalah bagaimana sinergi ini dapat memberdayakan kriyawan atau pengrajin untuk dapat berinovasi dan tidak melulu mengulang desain maupun karya yang sudah ada. Baik kriyawan maupun pengrajin dapat semakin sadar akan skill, material dan teknik produksi sebagai modal yang sudah dimiliki untuk dapat menciptakan produk yang transformatif, tidak hanya inovatif.

\section{Daftar Pustaka}

Gray, C., \& Burnett, G. (2009). Making sense : An exploration of ways of knowing generated through practice and reflection in craft. In L.K. Kaukinen (Ed.). In Proceeding of the Crafticulation and Education Conferenc. Helsinki: Finland: NordFo.

https:/www.edwinsgallery.com/kinetik perkembangan). (n.d.).

Niedderer, K. (2009). The culture and politics of knowledge in design research; how to develop discipline spesific methodolo- gies. In design and cultures. In 5th Annual Design Research Conference 2009. WA, USA: Washington State.

Nimkulrat, N. (2012). Hands-on intellect Integrating craft practice into design research. International Journal of Design: Taipei, 6(3).

Poser, J. (2008). Contemporary craft: The look of labor. In Art Education (p. 80-86.).

Tung, F. (2012). Weaving with rush ; exploring craft desin collaboration in revitalizing a local craft. Internatioanl Journal and Design, 6(3).

\section{Webtografi}

http://jewelrydesignsketchesideas2014.blogspot. co.id/2014

Kirsten Hassenfeld: http://www.bellwethergallery. com/artistsindex_01

https://www.edwinsgallery.com/kinetik_ perkembangan).

www.kominfo.go.id/content/detail 